\title{
Gaining engaged people to succeed Sustainable Development Goals (SDGs)
}

\author{
Novita Hidayati ${ }^{1, *}$ and Arum Etikariena ${ }^{1}$ \\ ${ }^{1}$ Department of Industrial and Organizational Psychology, Faculty of Psychology, University of \\ Indonesia, Depok 16424, Indonesia
}

\begin{abstract}
This research aims to determine the effect of team cohesion on work engagement with the mediating role of psychological empowerment. JD-R model is used to explain the phenomenon. We learn about how people who are engaged in ongoing working in team give an impact on people work engagement. Based on quantitative research from 557 participants from Indonesian military forces that were temporarily placed to carry out peace missions on conflict countries. By using Process to analyze data, we found that psychological empowerment partially mediate the relationship of team cohesion on work engagement (path a: Coeff $=$ $.29, \mathrm{SE}=.04, \mathrm{p}<.01,95 \% \mathrm{CL} .22$ to .37 ; path $\mathrm{b}$ : Coeff $=.23, \mathrm{SE}=.03, \mathrm{p}$ $<.01,95 \% \mathrm{CL} .17$ to .30 ; path c', Coeff $=.10, \mathrm{SE}=.03, \mathrm{p}<.01,95 \% \mathrm{CL}$ .04 to .17$)$.
\end{abstract}

\section{Introduction}

Compared with Millenium Development Goals (MDGs), Sustainable Development Goals (SDGs) involve more active participation from all sectors of society to succeed. The main channel of community that facilitated in UN activities are women, children and youth, indigenous peoples, Non-Governmental Organizations, local authorities, workers and trade unions, business and industry, scientific and technological community, and farmers. They also have to collaborate with others stakeholders such us: local communities, volunteer groups, and foundations, migrants and families, the elderly and people with disabilities who can preserve the sustainability of society in future generations [1].

Recognizing that collaboration and working in teams have an important role in the sustainability of society, the human resource capacities should be improved as well as management systems or products development to succeed all agenda of SDGs. Therefore through this research, we want to investigate how effective team cohesion give an impact to work engagement so the people are driven to achieve the expected goals. As we know that engaged employees provide beneficial effects not only for the organization but also for their self. Work engagement predicts employee performance, financial performance, organizationalssuccess [2]. It also represents the willingness to share positive affective on the environment [3]. It facilitates the achievement of important personal goals, increases well-being and psychological health. High-level work engagement related with the low-

\footnotetext{
* Corresponding author: novitahidayati@gmail.com
} 
level of anxiety and stress, low-level of burnout, high-level of mental resilience, and feel happier than disengaged employee [4-5]. Studies on work engagement rapidly increased for about two decades [6], but unfortunate the trend showed that employees have become increasingly disengaged [7]. Therefore, both researchers and HR practitioners are currently interested to investigate to get better solutions for that issued.

\section{Literature reviews}

\subsection{Work engagement}

Engagement can be described as the "hands, head and heart" inactive, full work performance [8]. It means engaged people allow themselves into what they do by getting fully involved. Furthermore, it is explained that 1). engaged people who activated their body and physical energy to participate, they have the willingness to use their tenacity and perseverance to prepare and improve (investing the hands); 2). engaged people who activated their mind, they have the willingness to think, to develop new thoughts and ideas to get solutions and actions, take responsibility to make decisions with the creative and innovative action plan, not only in term of rules and protocols (investing the head); 3 ). engaged employees permit themselves to become emotionally involved, finding meaning, and taking pleasure in what they do. They fully immerse with the flow of work activities even though they face problem and difficulties, have fun, and forget that they are working (investing the heart) [7].

Considering the explanation above, we agree that work engagement can measure undergo three dimensions, there are: 1). vigor means a high-level of energy and mental resilience while working and persistence in facing difficulties; 2). dedication, means a sense of significance, enthusiasm, inspiration, pride, and challenge; 3). Absorption means fully concentrated, being in a state of 'flow' characterized by focused attention, a clear mind, effortless concentration, loss of self-consciousness, distortion of time and intrinsic enjoyment [7]. These concepts are based on work engagement definition as a positive, fulfilling,work-related state of mind that is characterized by vigor, dedication, and absorption [9].

\subsection{Team cohesion}

Team cohesion is generally defined as attraction to the group and describes how much they liked one another as team members or how long they wanted to stay in the group [10]. According to the basic concepts of team cohesion, there are two key distinctions when defining team cohesion. There are between individual and group or team aspects, then between task and social cohesiveness. Based on that framework, definition of team cohesion includes: 1). group integration-task means perceptions of individual team member about the similarity and closeness within team task accomplishment; 2). group integrationsocial means perceptions of individual team member about closeness and bonding about team's social activities; 3). Individual attraction to group-task means feelings of individual team members about their involvement in the group task; 4). Individual attraction to groupsocial means feelings of individual team members about their involvement in the social interaction of the group [11].

Thereafter, researchers found that in a workplace context, team cohesion is just related to the following dimensions: 1). task cohesion means the extent to which the team is united and committed to achieving the work task; 2) social cohesion means the level of who the 
team members are like socializing together; 3 ). individual attraction to the group means the extent to which individual team members are attracted to the group [12].

\subsection{Psychological empowerment}

Psychological empowerment is the internal process or psychological state which individual or person being empowered [13]. In the workplace context, there are four dimensions that reliable to describe psychological empowerment. There are: 1). meaning means the level to which a work goal is valued relative to one's personal standards or criteria; 2). competence (self-efficacy) means an individual's belief that he or she has the power, skills, and capability to perform work tasks and activities; 3). self-determination means individual's belief that he or she has the power of choice and autonomy over behavior, processes, and decisions; 4) impact means an individual's perception that he or she can influence or control outcomes and make a difference at work [14-15].

\subsection{Theoretical overview of the JD-R model and engagement}

The concept of Job-Demands Resources (JD-R) model is widely used by researchers to understand the phenomenon of engagement. Research shows that work engagement is positively associated with job resources even though on highly job demands [16]. Furthermore, high job demands are positively associated with burnout and not negatively influence work engagement. Based on that research, we can learn about how to develop work engagement. Giving invests on job resources are more valuable rather than restricting job demands [7]. Others research found that personal resource is also given the contribution to work engagement. It may influence the perception of job resources and mediate the relation between job resources and work engagement [17].

Based on the theoretical model and characteristic of participants, we propose that psychological empowerment as a personal resource positively mediate the relation between work engagement and team cohesion as a job resource. Hypothesis: psychological empowerment is positively mediate the relation between work engagement and team cohesion.

\section{Method}

\subsection{Design, procedure, and participants}

This research used quantitative design. The online questionnaire and informed consent were sent to Indonesian military forces which are on duty as the military peacekeeper in two conflict countries. There are 557 respondents are convenient and agreed to become participants.

\subsection{Instruments}

We adopted the Utrecht Work Engagement Scale with 9-items (UWES-9) to measure work engagement [18]. The response format was a 7-point Likert scale for each, ranging from 0 (never) to 6 (always) and the scale revealed good reliability (Cronbach's alpha of present participants $=.886$ ). Team Cohesion (TC) scale with 10-items adapted for measuring team cohesion [12]. The response format was a 6-point Likert scale for each, ranging from 1(totally disagree) to 6 (totally agree) and the scale revealed good reliability (Cronbach's 
alpha at present participants $=.80$ ). Psychological Empowerment Scale (PEC) with 12items adapted for measuring psychological empowerment [14]. The response format was a 6-point Likert scale for each, ranging from 1(totally disagree) to 6 (totally agree) and the scale revealed good reliability (Cronbach's alpha at present participants $=.922$ ). All of the instrument adaptations involve changing the language into Bahasa and the wording of items to reflect an organizational context of the military environment.

\section{Results}

Data analyzed by Hayes Process Macro using SPSS program.

Table 1. Descriptive statistics and variable correlation.

\begin{tabular}{|c|c|c|c|c|c|}
\hline & $\mathrm{M}$ & $\mathrm{SD}$ & $\mathrm{WE}$ & $\mathrm{TC}$ & $\mathrm{PE}$ \\
\hline $\mathrm{WE}$ & 50,26 & 6,21 & & $.219^{* *}$ & $.334 * *$ \\
\hline $\mathrm{TC}$ & 44,83 & 7,98 & $.219^{* *}$ & & $.301 * *$ \\
\hline $\mathrm{PE}$ & 59,35 & 7,81 & $.334 * *$ & $.301 * *$ & \\
\hline
\end{tabular}

Table 1 presented the information on descriptive statistics and correlations between research variables: work engagement (WE), team cohesion (TC), psychological empowerment (PE).

Table 2. Results for the mediation effect of psychological empowerment.

\begin{tabular}{|c|c|c|c|c|c|c|c|c|c|c|c|c|}
\hline \multirow{2}{*}{ Mediator } & & \multicolumn{9}{|c|}{ M (PE) } & \multicolumn{5}{|c|}{ (WE) } \\
\cline { 2 - 13 } & & Coeff & SE & $\mathrm{P}$ & LLCI & ULCI & & Coeff & SE & $\mathrm{p}$ & LLCI & ULCI \\
\hline $\mathrm{X}(\mathrm{TC})$ & $\mathrm{a}$ & .29 & .04 & $\mathrm{p}<.00$ & .22 & .37 & $\mathrm{c}$ & .10 & .03 & $\mathrm{p}<.00$ & .04 & .17 \\
\hline $\mathrm{M}(\mathrm{PE})$ & & - & - & - & - & - & $\mathrm{B}$ & .23 & .03 & $\mathrm{p}<.00$ & .17 & .30 \\
\hline Constant & $\mathrm{i}_{1}$ & 46.13 & 1.80 & $\mathrm{p}<.00$ & 42.59 & 49.68 & $\mathrm{i}_{2}$ & 31.81 & 2.08 & $\mathrm{p}<.00$ & 27.73 & 35.89 \\
\hline & \multicolumn{10}{|l}{} \\
\hline
\end{tabular}

Note $: \mathrm{n}=557$

Bootstraps Sample Size $=5000$

Based on table 2, we know that there are positively significant on the relationship between team cohesion and work engagement (path c'; Coeff $=.10 ; \mathrm{SE}=.03 ; \mathrm{p}<.01$; $95 \% \mathrm{CL} .04$ to .17). Then, the relationship of team cohesion and psychological empowerment are also positively significant. It is supported (path a; Coeff $=.29$; $\mathrm{SE}=.04$; $\mathrm{p}<.01 ; 95 \% \mathrm{CL} .22$ to .37 ). Similiar with the relationship of psychological empowerment and work engagement, there is positively significant, so that it indicated that supported (path $\mathrm{b}$; Coeff $=.23 ; \mathrm{SE}=.03 ; \mathrm{p}<.01 ; 95 \% \mathrm{CL} .17$ to .30 ).

Table 3. Conditional total, direct, and indirect effects at team cohesion (X) on work engagement (Y).

\begin{tabular}{|l|c|c|c|c|c|}
\hline \multicolumn{1}{|c|}{ Mediator } & Coeff & SE & P & LLCI & ULCI \\
\hline the total effect of X on Y & .17 & .03 & $\mathrm{p}<.01$ & .11 & .23 \\
\hline the direct effect of X on Y & .10 & .03 & $\mathrm{p}<.01$ & .04 & .17 \\
\hline
\end{tabular}

Note $: \mathrm{n}=557$

Bootstraps Sample Size $=5000$

The point estimate of the direct effect of team cohesion was positive and statistically different from zero, as indicated by the point estimate of .50 and the $95 \%$ bias-corrected bootstrap confidence interval that was upper zero (.11 to .23). The statistical significance 
that shown in Table 3 indicated that there was partially mediated that happened. It means that psychological empowerment partially mediates the relationship between team cohesion and work engagement.

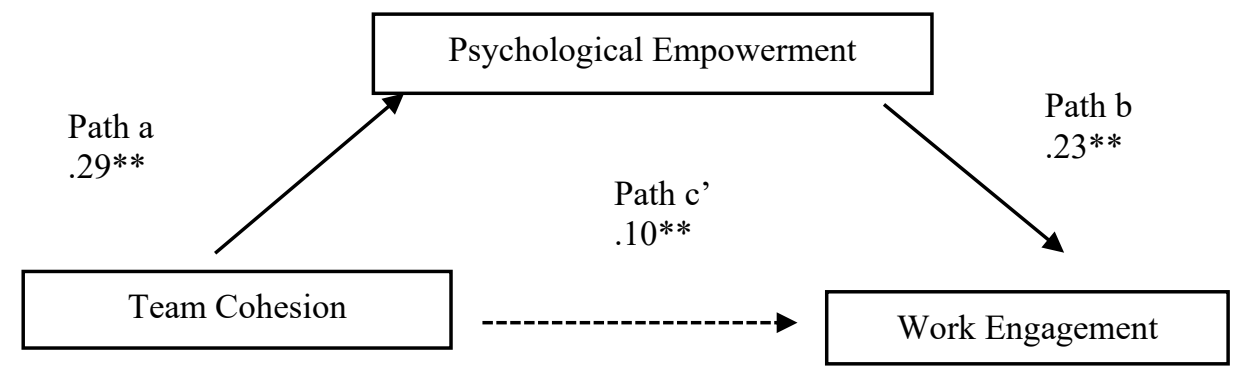

Fig. 1. Research model and hypothesis analysis

\section{Discussion}

In a military background, we know that team-based is their basic work. Cohesion has been raised since they entered the military education so that the situation has been carried away in everyday life. So, even if they are placed in a challenging environment, they can keep their work engagement from the high job demands. Moreover, high team cohesion can strengthen work engagement direct or indirectly through the psychological empowerment. The emotion contagion may play to one another so that work engagement can directly increase because of team cohesion. The other hand, some people believe that participation of individual on the team may give power and autonomy on their social life. Therefore his or her psychological empowerment become increase so that gives a positive impact for their work engagement [19]. People also more engaged with their work because of their belief that they can influence or control outcomes and make a difference work [14-15].

Regarding the achievement of the SDGs, this finding can be used as a consideration to make improvements, especially in the development of human resources that run the program. By activating work involvement, the person who runs the program will have more energy (vigor), dedication, fully concentrated (absorption) to achieve the expected goals. They have more energy to maintain the continuity of the program, more enjoyable, and many more benefits are obtained, such as better performance, organizational success [2], the willingness to share a positive affective environment [3], better well-being as well as psychological health [4-5].

\section{Conclusion}

The concept of Job-Demands Resources (JD-R) is still valid to explain the work engagement phenomenon. From this study, we can state that job resources that proven by team cohesion and personal resources that proven by psychological empowerment are giving a valuable contribution to work engagement. Psychological empowerment can play as partial mediation of the relationship between work engagement and team cohesion.

\section{Implication}

We can strengthen personal work engagement of both leaders and members of team or communities by team capacity building [20]. We can empower people to develop their 
senses of cohesion and also psychological empowerment, starting with assessment activities such as understanding each others personal needs activities then encouraging them to fulfill together on their communities, giving some challenges and autonomy, provide opportunities to develop their skills, knowledges, and capacities, completing activities by providing positively feedback and continuous monitoring.

\section{Acknowledgements}

This article is proposed for submission of PITTA 2018 (SCOPUS indexed international publication grants for University of Indonesia students).

\section{References}

1. U. Nations. Multi-stakeholder partnerships \& voluntary commitments. Available online at https://sustainabledevelopment.un.org/sdgs (2017)

2. A.M. Saks, Journal of Managerial Psychology 21, 600-619 (2006)

3. P.L. Costa, A.M. Passos, A.B. Bakker, R. Romana, C.F. Costa, Team Performance Management: An International Journal (2016)

4. C.H Maslach, W.B. Schaufeli, M.P. Leiter, Annual Review of Psy. 52, 397-422 (2001)

5. S. Crabtree, Gallup Management Journal 13, 1-4 (2005)

6. A.B. Bakker, S. Albrecht, Career Development International 23, 4-11 (2018)

7. B. Imperatori, Disengagement at Work Drivers and Organizational Practices to Sustain Employee Passion and Performance (Springer, Milan, 2017)

8. B.E. Ashforth, R.H. Humphrey, Human Relations 48, 97-125 (1995)

9. W.B. Schaufeli, M. Salanova, V. Gonzalez-Roma, A.B. Bakker, Journal of Happiness Studies 3, 71-92 (2002)

10. M. Hogg, The social psychology of group cohesiveness: From attraction to social identity (John Wiley, New York, 1992)

11. W.N. Widmeyer, L.R. Brawley, A.V. Carron, The measurement of cohesion in sports teams: The group environment questionnaire (Sports Dynamics, Ontario, 1985)

12. S.A. Carless, C.D. Paola, Small Group Research 31, 71-88 (2000)

13. S.T. Menon, Applied Psychology: An International Review 50, 153-180 (2001)

14. G. Spreitzer, Academy of Management Journal 38, 1442-1462 (1995)

15. B.T. Gregory, M.D. Albritton, T.Osmonbekov, Journal of Bussiness Psychology 25, 639-647 (2010)

16. W.B. Schaufeli, A.B. Bakker, Journal of Organizational Behavior 25, 293-315 (2004)

17. D. Xanthopoulou, A.B. Bakker, E. Demerouti, W.B. Schaufeli, Journal of Vocational Behavior 74, 235-244 (2009)

18. W.B. Schaufeli, M. Salanova, A.B. Bakker, Journal of Educational and Psychological Measurement 66, 701-716 (2006)

19. P.W. Speer, J. Hughey, Journal of Community \& Applied Social Psychology 6, 177187 (1996)

20. T. Cummings, C. Worley, Organization Development \& Change (Cengage Learning, USA, 2015) 